\title{
Application of Measurement Technology in the Teaching of Bridge Inspection Course
}

\author{
Chen Kongliang*, Zeng Qingxiang and Zhu Jiujiang \\ School of Civil Engineering and Architecture, Wuyi University, China
}

*Corresponding author: Chen Kongliang, School of Civil Engineering and Architecture, Wuyi University, China.

Received Date: April 05, 2021

Published Date: April 26, 2021

\begin{abstract}
Aiming at the current teaching situation of bridge inspection courses, this paper discusses the shortcomings and causes of the current bridge inspection courses in measurement technology teaching. For the purpose of training talents and improving measurement technology, we propose methods for teaching reform of measurement technology. Through measures such as increasing the test environment and improving laboratories, we can cultivate students' practical ability and awareness, improve teaching quality, and provide reference for related courses.
\end{abstract}

Keywords: Bridge; Instrument; Detection

\section{Introduction}

The rapid economic development has driven the construction of infrastructure and bridge projects into a period of rapid development. The increasing traffic volume which continues to increase has a greater impact on the structure of the bridge. Overloaded vehicles and heavy-duty vehicle fleets have a greater influence on the bridge structure. Bridge inspection is very important which is used as a means and guarantee to check the safe service of the bridge structure. The quality of inspection equipment directly affects the results of bridge inspection and evaluation. The accuracy and scientificity of measurement technology [1-3] is directly related to whether the bridge inspection can achieve the expected result and whether it can be the load of the bridge Ability and overall performance to make a correct evaluation. Therefore, through this teaching reform research, we will explore the application methods of testing instruments in bridge testing courses and provide reference for related courses.

\section{Classification of Bridge Inspection Instruments}

Bridge testing instruments can be divided into testing force size instruments, static testing instruments, dynamic testing instruments and so on. Among them, static testing instruments, dynamic testing instruments and non-destructive testing instruments are used more in bridge testing. Therefore, these types of instruments are the focus of course teaching. In addition, most of the bridge testing instruments are electrical testing instruments, so in the course of content teaching, students are required to have knowledge of electricians. The bridge appearance inspection, and load test and other links require leveling, and total station, and rebound tester, and strain gauge, while the dynamic test is mainly carried out by auxiliary equipment such as acceleration sensor, dynamic signal acquisition and analysis system.

\section{The Current Status of Teaching Use of Bridge Testing Instruments}

\section{The testing equipment is updated quickly}

At present, there are many testing instruments, and the update speed is relatively fast. There are many electrical measuring instruments and equipment in the bridge laboratory. Various advanced instruments and equipment are constantly emerging, and old equipment is constantly aging and eliminated. Bridge testing technology is developing towards intelligent and wireless discovery. In addition, there are many testing instruments and 
frequent equipment. The use or non-use of the equipment will deteriorate the equipment, and the laboratory equipment cannot be updated very frequently, which causes the equipment used in the student experiment to lag behind the actual equipment used. The current instruments are updated rapidly, and the instruments purchased a few years ago are relatively backward, so these instruments are also difficult to meet the teaching requirements of current detection technology.

\section{The theory of measuring instruments involves many theories}

There are a large number of bridges testing instruments, involving many knowledge points and theories. The relatively simple knowledge points include ultrasonic rebound instruments and the mechanics principles of strain gauges. Among them, the more complex content includes influence line loading, lateral distribution coefficient calculation, and pile foundation inspection. If these preliminary knowledge points are not mastered, the corresponding teaching will be difficult to achieve the expected goals. If only staying at the level of mastering the use of testing instruments, the teaching effect needs to be further improved.

\section{Data post-processing teaching is more difficult}

The more difficult part in the teaching of testing instruments and equipment is the data post- processing process. Especially in the limited course teaching, it is unrealistic if you need to master the larger instrument post-processing process. Therefore, in the course teaching, some commonly used instruments and equipment are the focus of teaching, such as data processing of rebound hammers, data processing of steel corrosion testers, and data processing of load tests. For example, the original data obtained from the test must be processed and analyzed through data, so that the index for evaluating the bearing capacity of the bridge structure can be obtained. Therefore, in order to improve the accuracy of the data, it is necessary to process the collected data. However, the postprocessing of this part of the data is difficult, and it is difficult to learn in a relatively short period of time.

\section{Teaching Reform on the Use of Bridge Testing Instruments}

\section{Improve measurement technology}

The current measurement technology still has a lot of room for improvement in terms of accuracy and adaptability. In order to obtain accurate test data, it is necessary to use simple, accurate and applicable bridge measurement technology and instruments. The adhesion of strain gauges plays a vital role in the bridge load test, and this part of the content is also a time- consuming process, so it can be used with faster adhesion, high test accuracy, recyclability and convenient data processing. The use of the instrument improves the accuracy of data acquisition and data processing. In addition, it is necessary to strengthen the study of instrument use theory. This link is essential, which can effectively reduce students' errors in operating the instrument and improve the efficiency of using the instrument.

\section{Practical teaching can be used as an auxiliary means of theoretical teaching}

Practical teaching is more flexible than traditional multimedia teaching, which interacts with students more closely and intuitively. It can provide a vivid and intuitive learning environment, as well as pictures, text, and experiments. Sound, images and other rich expression skills can be used to help students learn. Through these contents, students' enthusiasm for learning can be effectively improved and the learning effect can be improved.

\section{Strengthen laboratory construction}

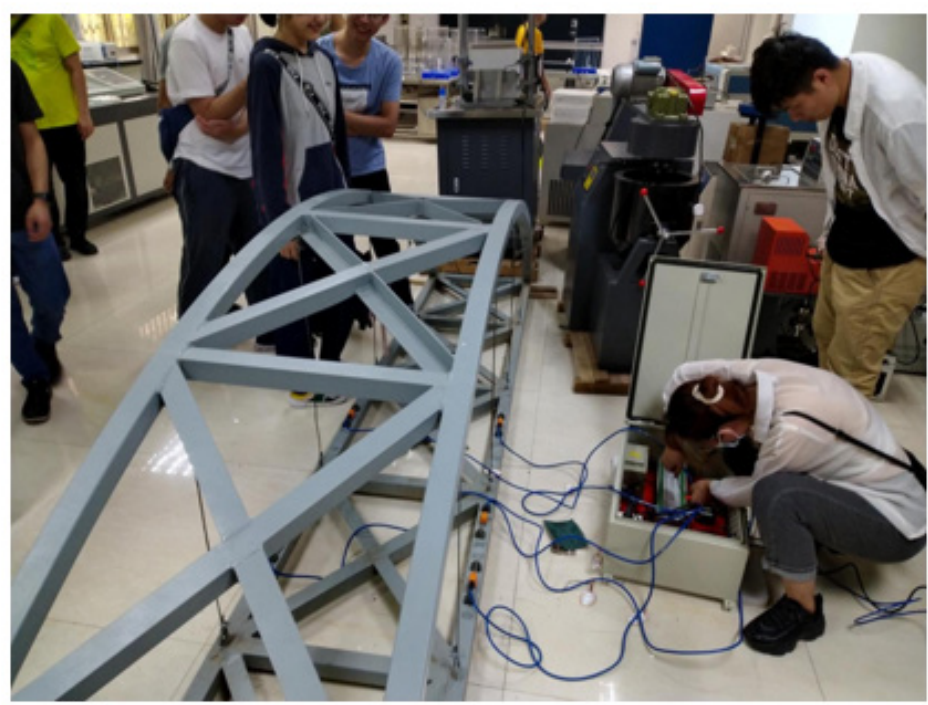

Figure 1: Strain gauge installation 


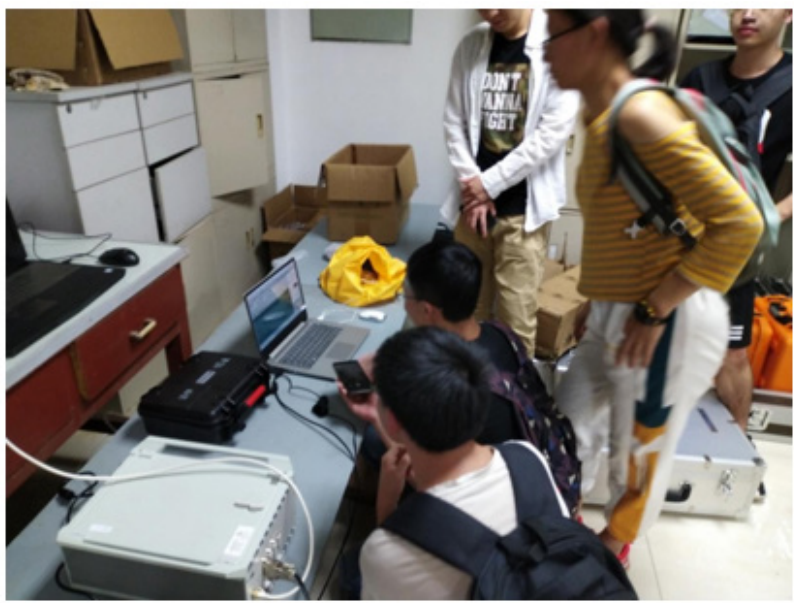

Figure 2: Live load data collection.

The load test plan needs to be optimized. It takes a long time to pass the actual load test, and usually requires preliminary preparation and on-site testing. Therefore, the actual load test practice is carried out in the difficult course content. While optimizing the static load test technology, it is also necessary to carry out research on the dynamic load test technology so that the collected dynamic test data can more effectively evaluate the bridge accurately. This is a problem that needs to be considered in the course content. By adopting bridge model test instead of actual bridge inspection, pasting instruments, loading and data collection on the model, and finally enabling students to master the use of load test instruments, the preparation of loading plans, and related principles, which can also effectively improve teaching effect (Figures 1,2).

\section{Strengthen the study of related theories}

Materials mechanics, structural mechanics, bridge engineering and structural dynamics and other related knowledge are the theoretical basis of bridge detection load test. Therefore, the relevant course content is explained clearly in teaching to enable students to better master this part of knowledge. When the abstract content of the course is involved, it is easier to achieve the expected teaching effect by combining the photos of the field experiment or the live video. Applying what you have learned to use to promote learning can better improve theoretical understanding and better guide practice.

\section{Strengthen the training of measurement technology}

To strengthen the training of measurement technology, it is necessary not only to teach the content of the course, but also to give play to independent learning ability and professional standards which are able to use professional knowledge and professional methods to solve practical problems in engineering. The content of measurement technology is more, but the main content is the learning of static testing equipment and dynamic testing equipment, students have enough time to touch and use the equipment by increasing the time of practical teaching. In addition, to strengthen the training of measurement technology, it is also necessary to ensure that there is enough equipment, so as to ensure that each student has enough time to learn the equipment when the students are studying in groups (Figure 3).
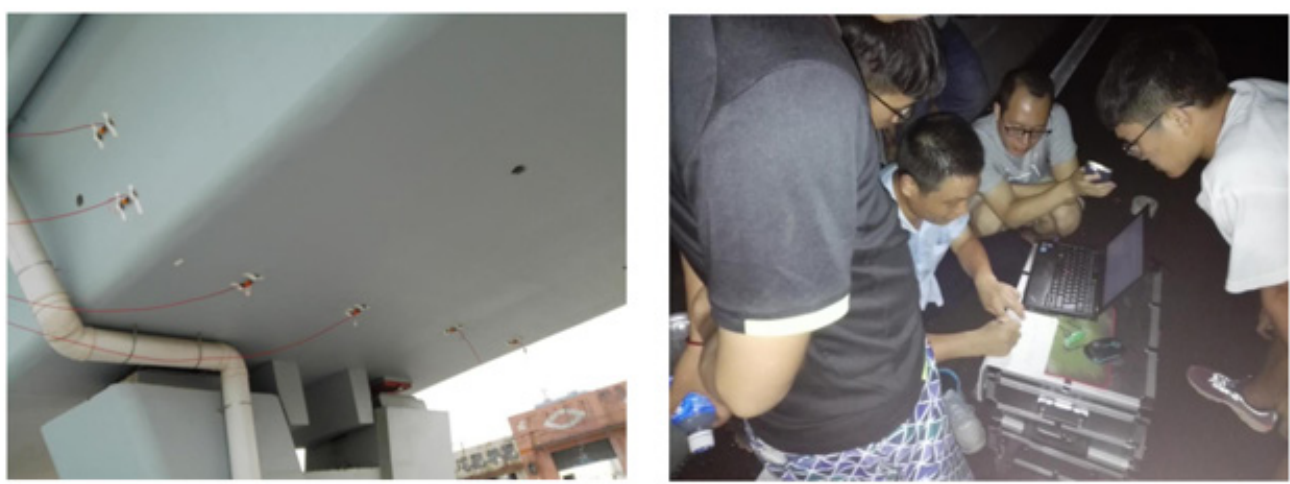

Figure 3: Real bridge data collection. 


\section{Increase the study of report collation}

Bridge inspection reports include visual inspection reports, load test reports, and non- destructive inspection reports. The organization of reports includes checking original records, and checking theoretical calculation results, and drawing observation point stress-strain curves, and deformation observation curves. These curves can clearly reflect the deformation trend and amplitude, which are very useful for preliminary judgment of whether the bridge is working properly and analyzing the data to summarize the bridge deformation process and the reasons for the deformation law analysis, and then judge whether the bridge is working normal. According to the analysis of the cause, make statistics on the measured data and find the law from it (Figures $4,5)$.

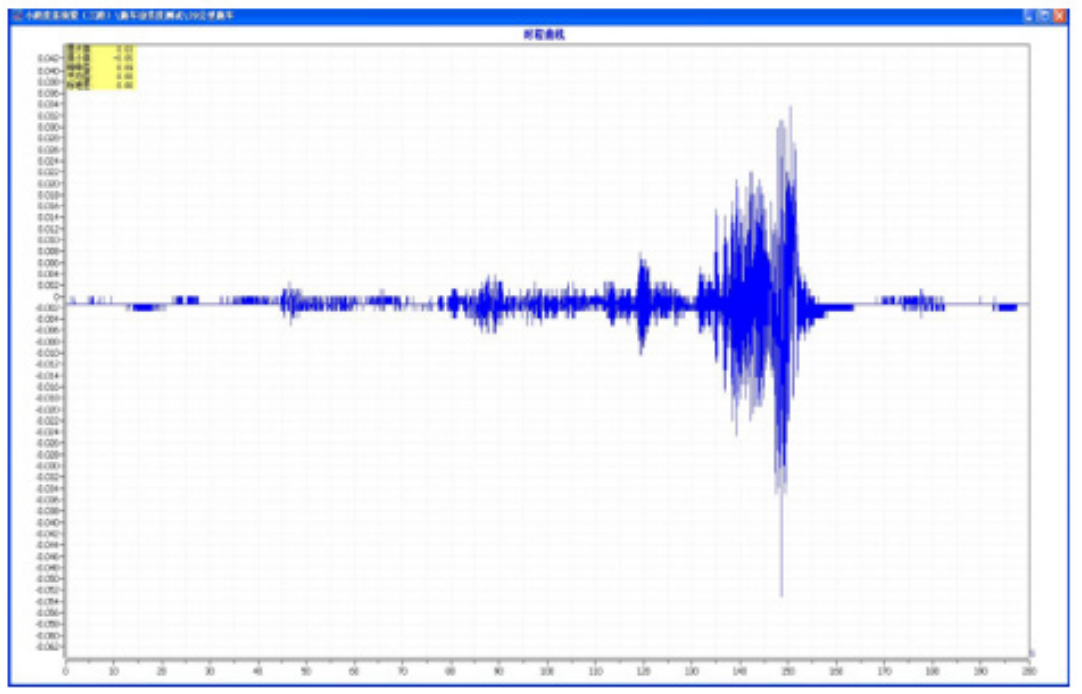

Figure 4: Post-processed data (1).

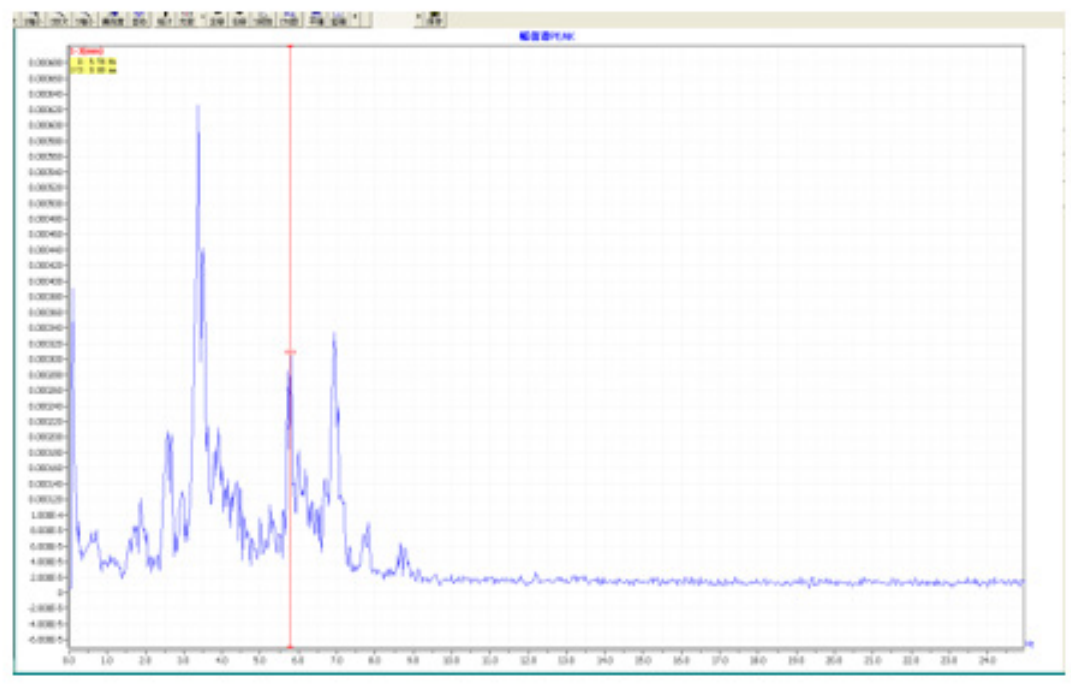

Figure 5: Post-processed data (2).

\section{Conclusion}

Bridge measurement technology involves the comprehensive application of multiple courses and requires strong theoretical knowledge. The enhancement of measurement technology also requires continuous practice. Based on the foregoing, several methods that can effectively improve the teaching effect of bridge load test techniques are drawn.

1. Improving the measurement technology and optimizing the teaching experiment program can better improve the enthusiasm of students in learning and improve the practical ability of students. 
2. Consolidating the relevant basic theories and mastering the relevant basic knowledge can better improve the teaching effect

3. Strengthening the construction of laboratories and increasing the learning in post-processing links can effectively cultivate the innovation ability and independent learning ability of the students.

\section{Acknowledgment}

None.

\section{Conflict of Interest}

No conflict of interest.

\section{References}

1. Alampalli S, Frangopol DM, Grimson J, Marvin WH, David E Kosnik, et al. (2021) Bridge Load Testing: State-of-the- Practice. Journal of Bridge Engineering. 26(3).

2. Zhao Peili, He Xijia (2021) Research on dynamic data monitoring of marine bridge steel structure building information based on BIM model Arabian Journal of Geosciences. 14(4).

3. Xuan Jiming, Shen Fuxing (2007) Research and engineering application of bridge inspection technology[J]. Bridge Construction. (1): 158-160. 